\title{
Analysis of Water Cycle in Weizhou Island of Beihai City, Guangxi Province, Part II: Study On Groundwater Exploitation Plan
}

\author{
Zhang Shunfu ${ }^{1,2, a}$, Liu Changjun ${ }^{1,2}$, Li Chuanke ${ }^{3}$, Long Sili ${ }^{3}$, Zhou Jian ${ }^{4}$ and Zhang Qiyi ${ }^{1,2}$ \\ ${ }^{1}$ China Institute of Water Resources and Hydropower Research, Beijing, 100038, China \\ ${ }^{2}$ Research Center on Flood\&Drought Disaster Reduction of the Ministry of Water Resources, Beijing, 100038, China \\ ${ }^{3}$ Guangxi Water\&Power Design Institute, Nanning, Guangxi Province, 530023, China \\ ${ }^{4}$ Northwest Institute of Ecology and Environmental Resources, Chinese Academy of Sciences, Lanzhou, Gansu Province, 730000 , China
}

\begin{abstract}
To relieve the drop of groundwater and seawater intrusion in Weizhou Island caused by overexploitation, the analysis model of precipitation-runoff and variable-density groundwater flow in Weizhou Island was established and the model's parameter identification results were used to investigate groundwater level and seawater/freshwater interface changes under different groundwater exploitation plans. Thereafter, a rational groundwater exploitation plan could be made to prevent the lowering of groundwater levels caused by ground water overexploitation and ecological deterioration caused by seawater intrusion. This could help accelerating the recovery of ground water and maintaining ecological system.
\end{abstract}

\section{Introduction}

About half of the world's population lives within $100 \mathrm{~km}$ of the coastline, where the population density is twice the world's average. Groundwater is one of the important fresh water resources in coastal areas because of its wide distribution and excellent water quality. With the development of society and the construction of urbanization, the freshwater demand in coastal areas increases, and the phenomenon of groundwater overexploitation generally occurs. The overexploitation of groundwater in coastal areas will break the original water balance and cause seawater intrusion. Overexploitation of groundwater is common in China's coastal areas. In 2003, 2,457 $\mathrm{km}^{2}$ seawater invaded because of groundwater overexploitation in China. The invaded provinces include Liaoning, Hebei, Shandong,Jjiangsu, Guangdong, Guangxi and Hainan. Seawater intrusion may cause many hazards, such as polluting underground/surface freshwater resources, affecting agricultural development, and damaging terrestrial ecosystems supported by groundwater. Seawater intrusion has become a serious environmental hydrogeological problem. Therefore, it is of great theoretical significance and scientific value to carry out research on groundwater exploitation and seawater intrusion, to formulate reasonable plans for groundwater exploitation and utilization and management in coastal and island areas, and to prevent and mitigate the hazards of seawater intrusion.

\section{Governing equation and its solution}

\footnotetext{
a Corresponding author: zhangsf@iwhr.com
}

Affected by dissolved substances, the density of seawater is different from that of fresh water. The governing equations are the mass conservation of water flow, the density state equation and the solute transport equation. The governing equation, the solving condition and its dispersion can be found in the literature [1]. The solution is made by using the SEAWAT software and the control equation is discretized by the finite difference method [2].

\section{Identification of solute transport parameters}

On the basis of the identification of hydrogeological parameters such as rainfall infiltration coefficient, permeability coefficient of each layer, water availability, water storage coefficient, etc. in literature [1], the solute transport parameters were identified, which mainly included solute transport parameters such as hydrodynamic dispersion. The recognition and verification of solute transport model mainly follows the following principles :(1) the simulated concentration should be basically consistent with the actual concentration, that is, the shape of simulated contour should be similar to the measured ones;(2) the dynamic process of simulating chloride ion concentration should be basically similar to the measured dynamic process, and the simulation should be similar to the measured chloride ion concentration process line shape;(3) the solute transport parameters identified should conform to the actual hydrogeological conditions.

\subsection{The parameter identification method}


PEST software is used as a parameter identification tool. The PEST software based on Gauss-MaquardtLevenberg (GML for short) developed by Doherty is an excellent representative of the automatic calibration model [3]. PEST software has been successfully applied in parameter identification of surface water and groundwater model [4-7].

\subsection{Model parameter zoning}

Due to the limitations of data, only part of the water quality data of the phreatic aquifer is available currently. Here, the dispersion parameter zoning of the unconfined aquifer is only performed. The dispersion partition of the phreatic aquifer is shown in Figure 1.

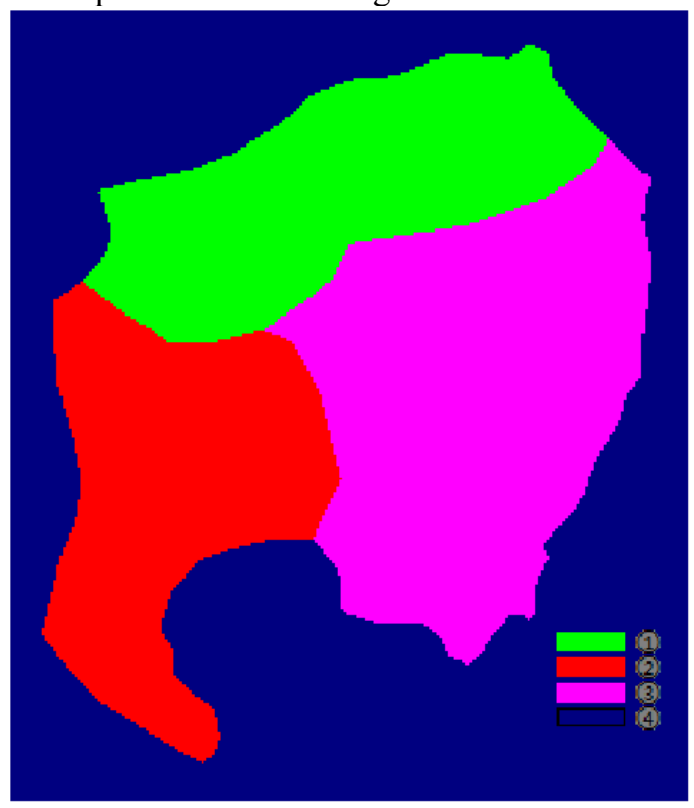

Figure 1. Distribution diagram of dispersion of phreatic aquifer.

\subsection{Observation well information}

The simulation period is from February, 2012 to June, 2013.Three water quality observation wells were selected to observe the chloride ion concentration value as the concentration reference value for parameter identification. The well numbers and locations are shown in Table 1. The three observation wells are distributed in the unconfined aquifer, and the specific distribution is shown in Figure 2.

Table 1. Observation Well Information (UTM 49N).

\begin{tabular}{|c|c|c|c|c|}
\hline No. & Name & $\boldsymbol{x}_{\mathbf{1}}$ & $\boldsymbol{x}_{\mathbf{2}}$ & aquifer \\
\hline 1 & ZTMC & 301998 & 2328939 & Unconfined \\
\hline 2 & BGC & 304186 & 2330554 & Unconfined \\
\hline 3 & HJJ & 303643 & 2326984 & Unconfined \\
\hline
\end{tabular}

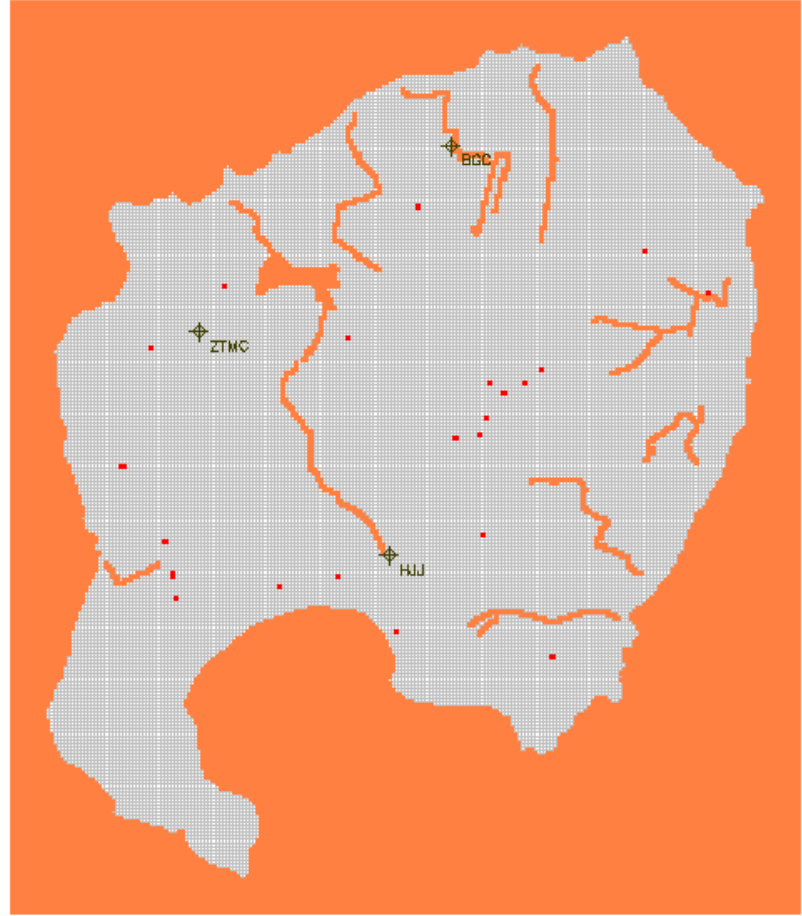

Figure 2. Distribution of water quality observation wells.

\subsection{Analysis of simulation results}

The comparison of calculated chloride ion concentration value and observed concentration value of the three wells is shown in Figure 3-5.

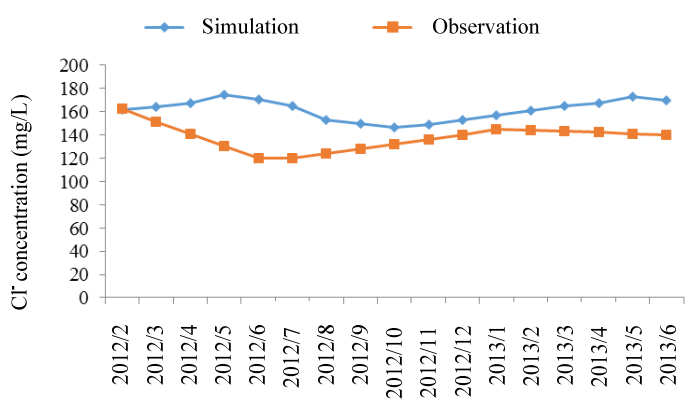

Figure 3. Chlorine ion concentration comparison for ZTMC.

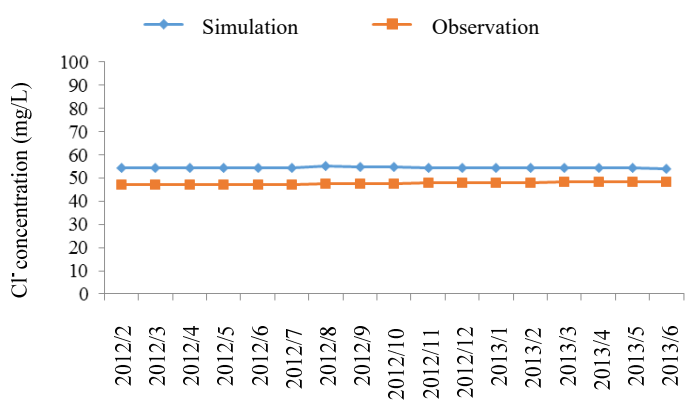

Figure 4. Chlorine ion concentration comparison for well BGC. 


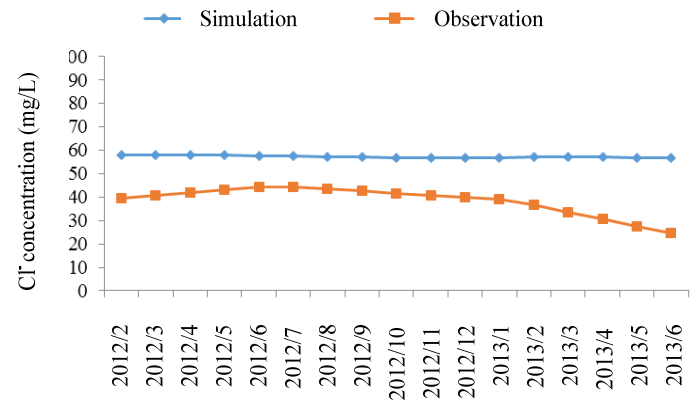

Figure 5. Chlorine ion concentration Comparison for well HJJ.

It can be seen that the calculated chloride ion concentration value of the observation wells is approximately the same as the observed one. Also, judging from the comparison results, the overall fitting trend of the concentration of each point is good except for certain errors in some time periods, which indicates that the recognized hydrodynamic dispersion can correctly reflect the actual situation of the seawater intrusion of Weizhou Island.

Table 2. Dispersivity of the unconfined layer after identification.

\begin{tabular}{|c|c|c|c|c|}
\hline Zone No. & (1) & (2) & (3) & (4) \\
\hline Vertical dispersivity(m) & 1.0 & 5.0 & 10.0 & 13.0 \\
\hline Horizontal dispersivity(m) & 0.1 & 0.5 & 1.0 & 1.3 \\
\hline
\end{tabular}

Table 3. Dispersivity of other layers after identification.

\begin{tabular}{|c|c|c|}
\hline Layer & $\begin{array}{c}\text { Vertical } \\
\text { dispersivity(m) }\end{array}$ & $\begin{array}{c}\text { Horizontal } \\
\text { dispersivity(m) }\end{array}$ \\
\hline Weak permability & 1.8 & 0.18 \\
\hline First confined & 25 & 2.5 \\
\hline Second confined & 37 & 3.7 \\
\hline Third confined & 45 & 4.5 \\
\hline
\end{tabular}

\section{Comparison of different exploitation plans}

In order to predict the water level change and seawater intrusion in Weizhou Island after 50 years under different exploitation schemes, five exploitation schemes are considered :(1) keep the original exploitation amount of $4080 \mathrm{~m}^{3} / \mathrm{d} ;(2)$ reduce the exploitation amount to half of the original amount: $2040 \mathrm{~m}^{3} / \mathrm{d} ;(3)$ increase the exploitation amount by 1.5 times of the original amount to $6120 \mathrm{~m}^{3} / \mathrm{d} ;(4)$ increase the exploitation amount to $8800 \mathrm{~m}^{3} / \mathrm{d}$. The annual rainfall is $1373.6 \mathrm{~mm}$ based on the average rainfall of the previous 50 years.

\subsection{Plan 1: maintaining $4080 \mathrm{~m}^{3} / \mathrm{d}$}

Changes in water level and intrusion of seawater in the aquifers of Weizhou Island after 50 years are shown in Figure 6(a)-(e). It can be seen from the figures that after 50 years, the seawater intrusion range of the phreatic aquifer has been slightly reduced and the water quality has been slightly improved. This is mainly because the water exploitation of the phreatic aquifer is mainly concentrated in the villages and towns, which is basically under control. Moreover, the main source of daily water of the villages and towns is tap water. The intrusion range of seawater in confined aquifer does not change obviously(note: Seawater intrusion is considered when the concentration of chloride ion in groundwater is greater than $250 \mathrm{mg} / \mathrm{L}$, and the yellow part in the figure is the range of seawater intrusion, and the red line is the boundary of Weizhou Island).

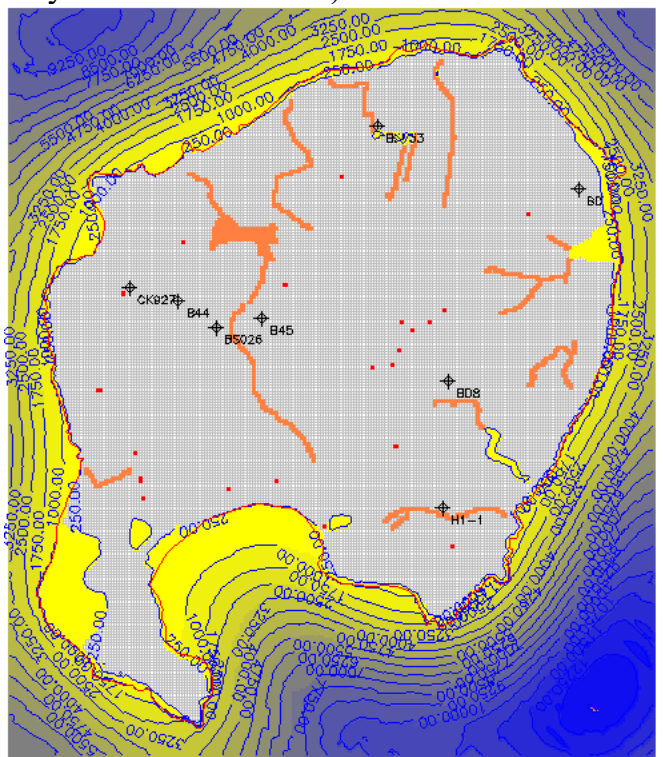

Figure 6(a). Seawater intrusion in unconfined layer.

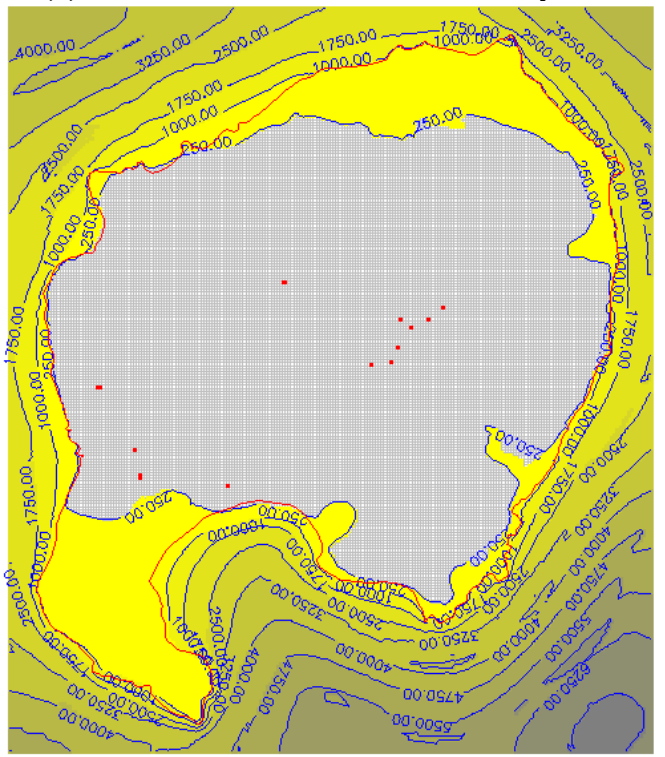

Figure 6(b). Seawater intrusion in weak permeable aquifer. 


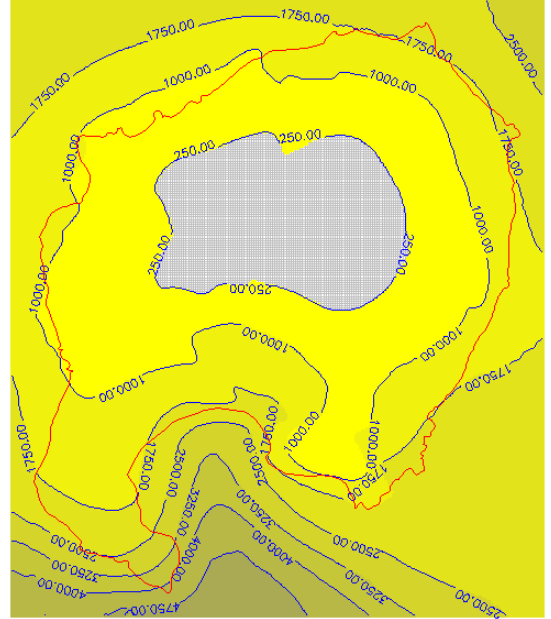

Figure 6(c). Seawater intrusion in the third confined aquifer.

\subsection{Plan 2: Reducing to $2040 \mathrm{~m}^{3} / \mathrm{d}$}

After reducing the exploitation amount to $2040 \mathrm{~m}^{3} / \mathrm{d}$, the simulated distribution of the water level and seawater intrusion of each aquifer are shown in Figure 7(a)-(e). In comparison with the seawater intrusion under working condition I, it was found that the invasion range of the phreatic aquifer and the confined aquifer was significantly smaller, and the groundwater quality was improved.

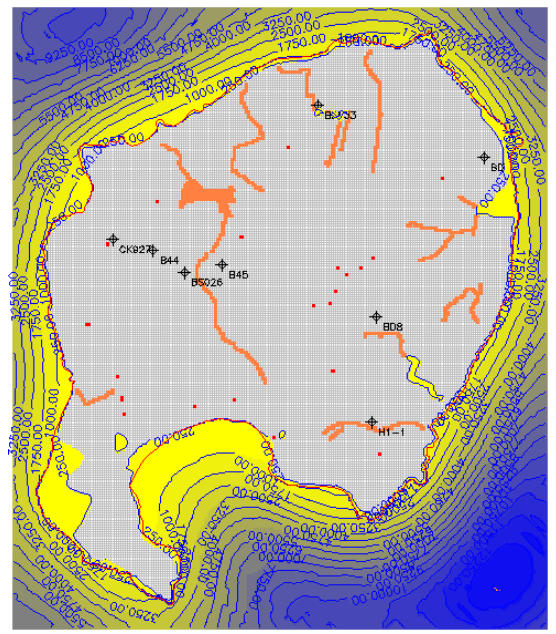

Figure 7(a). Seawater intrusion in unconfined layer.

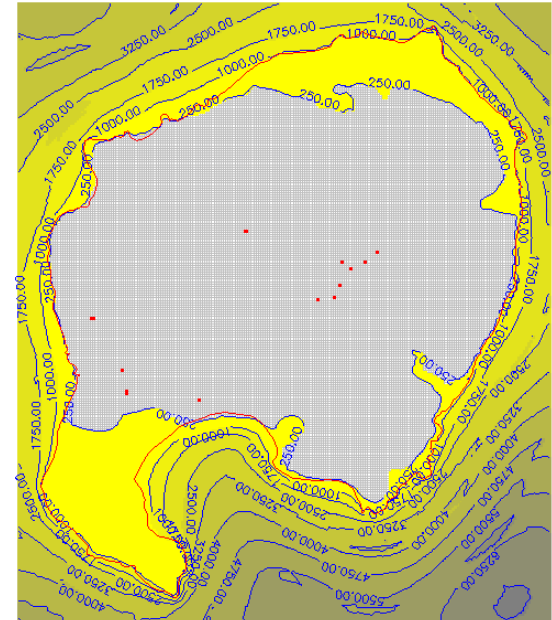

Figure 7(b). Seawater intrusion in weak permeable aquifer.

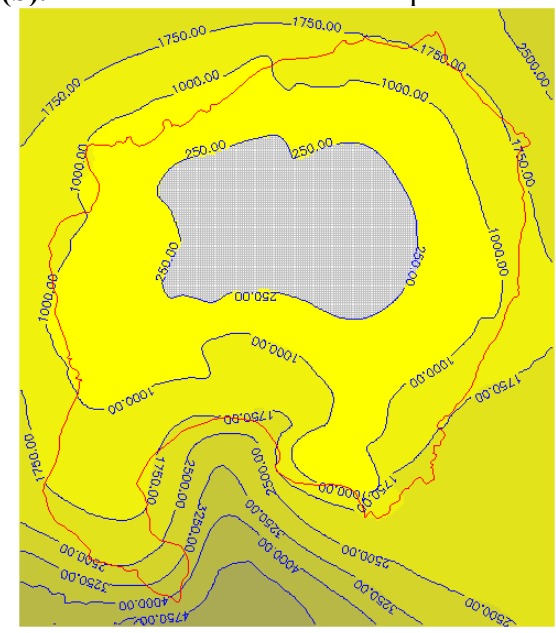

Figure 7(c). Seawater intrusion in the third confined aquifer.

\subsection{Plan 3: Increasing to $6120 \mathrm{~m}^{3} / \mathrm{d}$}

The water level distribution and seawater intrusion range of all aquifers in Weizhou Island after 50 years are shown in Figure 8(a)-(e). By comparing the first two conditions, it is found that under the current exploitation amount, the seawater intrusion range of both the phreatic aquifer and the confined aquifer is larger than the first two, the water quality is deteriorated, and the available water resource quantity is reduced. 


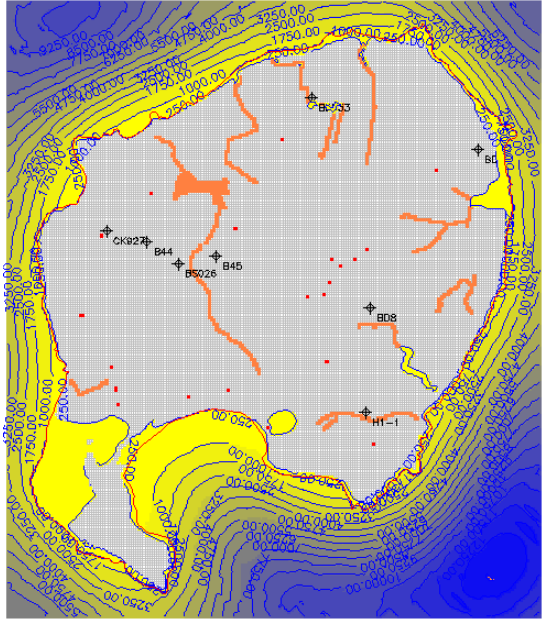

Figure 8(a). Seawater intrusion in unconfined layer.

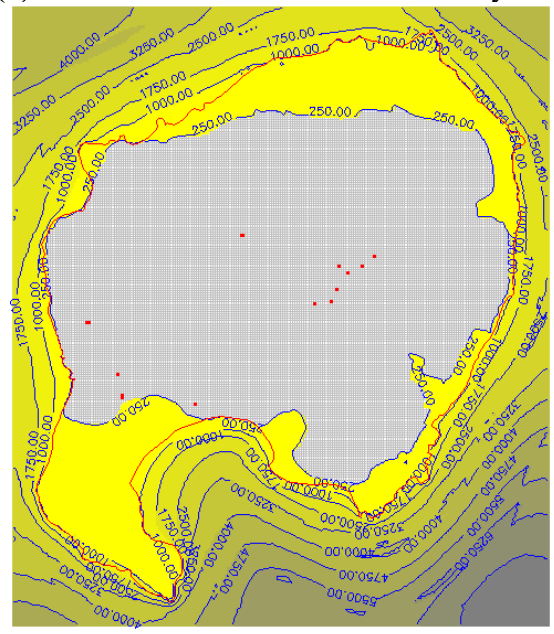

Figure 8(b). Seawater intrusion in weak permeable aquifer.

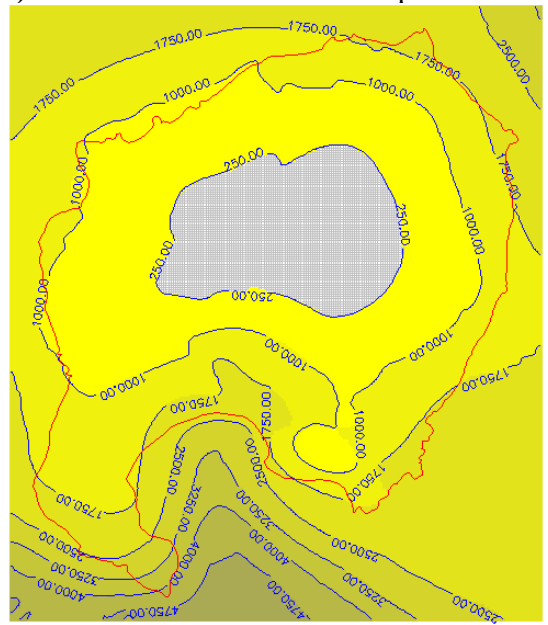

Figure 8(c). Seawater intrusion in the third confined aquifer.

\subsection{Plan 4: Increasing to $8800 \mathrm{~m}^{3} / \mathrm{d}$}

After increasing the daily exploitation amount to $8800 \mathrm{~m} 3 / \mathrm{d}$, the annual total exploitation volume has increased significantly. As shown in Figure 9(a)-(e), due to the significant increase in the exploitation amount of underground water in the confined aquifer, the chloride ion concentration in both the unconfined aquifer and the confined aquifer gradually increased after 50 years, the seawater intrusion range significantly increased, and the water quality in the confined aquifer became worse.

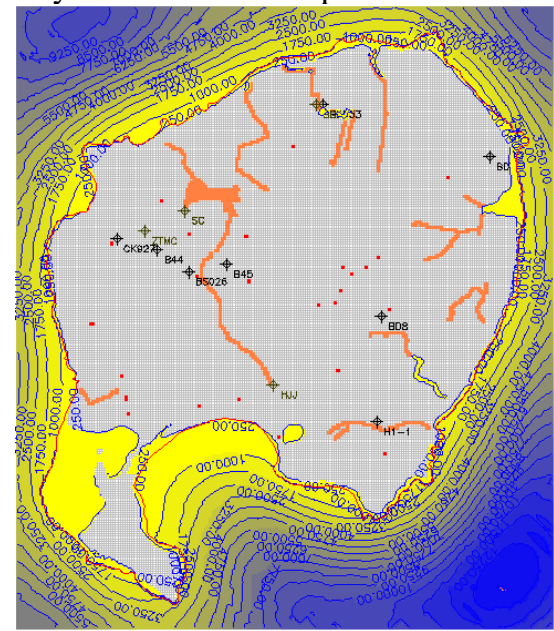

Figure 9(a). Seawater intrusion in unconfined layer.

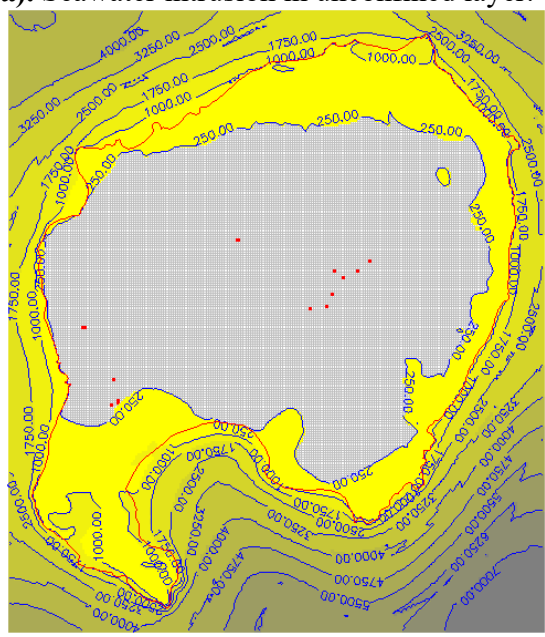

Figure 9(b). Seawater intrusion in weak permeable aquifer.

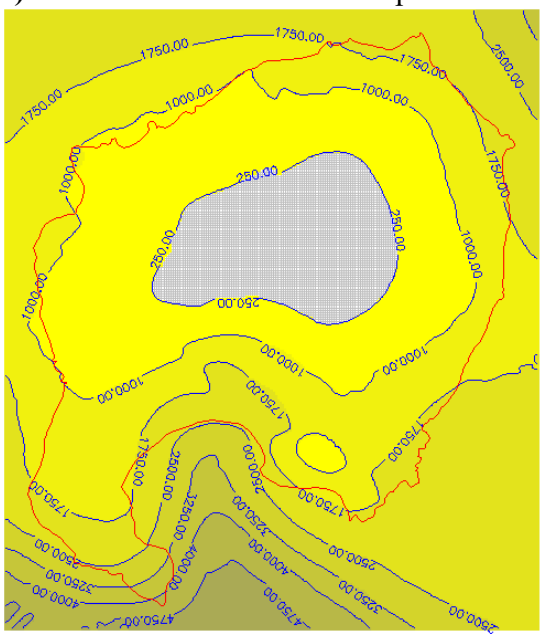

Figure 9(c). Seawater intrusion in the third confined aquifer. 


\subsection{Results analysis}

Weizhou Island is an independent hydrogeological unit surrounded by sea. Its underground fresh water is a "floating" lens above the sea water. Rainfall is the only natural source of groundwater resources in Weizhou Island. The average rainfall in the last 50 years of Weizhou Island is $1373.6 \mathrm{~mm}$. The calculated rainfall infiltration quantity was $13709 \mathrm{~m}^{3} / \mathrm{d}$ and the annual replenishment quantity was 5.4 million $\mathrm{m} 3$. However, the actual rainfall recharge infiltration into the subsurface aquifer cannot be fully exploited, and most of the groundwater resources are extracted from the confined aquifer. The groundwater in the subsurface aquifer must pass through the clay layer of the aquitard, which has the effect of "water blocking", before it can enter the subsurface confined aquifer for exploitation and utilization.

The water level of each aquifer basically increases with the increase of time. The larger the exploitation amount is, the more obviously the water level drops, and vice versa. According to the principle of water balance, under the condition that the storage of underground fresh water resources in the confined aquifer remains unchanged, combined with four different changes of water level and scope of seawater intrusion, it is suggested that the industrial and agricultural exploitation amount in Weizhou Island should be controlled under $4080 \mathrm{~m}^{3} / \mathrm{d}$, and the exploitation amount in phreatic aquifer of the groundwater resources should be less than $15 \%$ of the total production, with the annual maximum production as 1.752 million $\mathrm{m}^{3}$. In this way, the daily water demand of Weizhou Island can be met and the sustainable water utilization and water balance can be maintained.

\section{Conclusion}

Based on the groundwater exploitation requirements of Weizhou Island in Beihai city, Guangxi, this paper established the precipitation - runoff and variable density groundwater flow analysis model of Weizhou Island, and identified the solute transport model parameters through the historical data of rainfall and chloride concentration. Based on this, this paper studied the distribution of underground water and seawater intrusion under the condition of four different groundwater exploitation schemes, and obtained the reasonable groundwater exploitation amount. It is suggested that that the industrial and agricultural exploitation amount in Weizhou Island should be controlled under $4080 \mathrm{~m}^{3} / \mathrm{d}$ and the exploitation amount in phreatic aquifer of the groundwater resources should be less than $15 \%$ of the total production. In addition, it is recommended to strengthen the monitoring of chloride ions in groundwater in the southwest and north of Weizhou Island, especially to increase the monitoring arrangement of chloride ions in pressurized water, so as to facilitate the monitoring and control of seawater intrusion on Weizhou Island and help to develop and adjust the groundwater exploitation plan.

\section{Acknowledgments}

This paper was jointly supported by National Key R\&D Program of China (Mechanism of Landslide due to Seepage in expansive soil bank slope and dam; 2017YFC1501201), Key R\&D Program of Guangxi(Study on Modeling and Joint Operation of Surface Water/Groundwater Circulation in Weizhou Island, Beihai City, Guangxi, JZ0202112016), Hunan Water Science \&Technology Plan(Research on flash flood simulation and forecasting methods based on Geomorphologic Hydrological Response Unit in Hunan mountainous areas; Hunan Water Science \& Technology Plan[2017]230-35); Key R\&D Program of Beijing (Beijing 2018 Annual Mountain Flood Disaster Prevention Project - Monitoring and Early Warning Platform and Monographic Study;JZ0203112018); Science \& technology project of Guangxi Water Resources Department (Development and application of dam safety management information system for Guangxi reservoir, 201614) and National Key R\&D Program of China (Research on key technologies and relevant equipments for emergency risk-elimination and quick repairment of flood discharge structures in the south to North Water Transfer Project, 2017YFC0405004).

\section{References}

1. Zhang S. f., Liu C. j., Li C. ki, Long S. 1., Zhou J. and Zhang Q. y., Analysis of Water Cycle in Weizhou Island of Beihai City, Guangxi Province, Part I: Theory and Model Parameter Identification: Matec Web of Conferences (to be published)

2. Guo, Weixing, and Langevin, C.D., User's Guide to SEAWAT: A Computer Program for Simulation of Three-Dimensional Variable-Density Ground-Water Flow: Techniques of Water-Resources Investigations Tallahassee,Florida: US Geological Survey.1-87(2002)

3. Doherty J. PEST: Model-independent parameter estimation and Uncertainty Analysis, User manual: 7th ed [EB/OL]. Brisbane, Queensland, Australia:Watermark Numeric Computing(2018)

4. Iskra I, Droste R. Application of non-linear automatic optimization techniques for calibration of HSPF [J]. Water Environment Research, 79(6): 647659(2007)

5. Skahill B E, Baggett J S, Frankenstein S, et al. More efficient PEST compatible model independent model calibration[J]. Environmental Modelling \& Software, 24(4): 517-529(2009)

6. Meyer S C, Lin Y F, Roadcap G S. A hybrid framework for improving recharge and discharge estimation for a three-dimensionalgroundwater flow model [J]. Ground Water, 50(3): 457-463(2012)

7. Manskopf T, Braxein A, von Schwarzenberg T. Large Scale Groundwater Modelling and Calibration $[\mathrm{M}]$. Geoecology and Computers. Leiden: AA Balkema Publishers: 503-507(2000) 